\title{
Emerging roles of a pivotal IncRNA SBF2-AS1 in cancers
}

\author{
Qian Lu' ${ }^{1}$ Jun Lou ${ }^{1}$, Ruyun Cai ${ }^{2}$, Weidong $\operatorname{Han}^{1 *}$ and Hongming Pan ${ }^{1 *}$
}

\begin{abstract}
Long non-coding RNAs refer to transcripts over $200 \mathrm{nt}$ in length that lack the ability to encode proteins, which occupy the majority of the genome and play a crucial role in the occurrence and development of human diseases, especially cancers. SBF2-AS1, a newly identified long non-coding RNA, has been verified to be highly expressed in diversiform cancers, and is involved in processes promoting tumorigenesis, tumor progression and tumor metastasis. Moreover, upregulation of SBF2-AS1 expression was significantly related to disadvantageous clinicopathologic characteristics and indicated poor prognosis. In this review, we comprehensively summarize the up-to-date knowledge of the detailed mechanisms and underlying functions of SBF2-AS1 in diverse cancer types, highlighting the potential of SBF2-AS1 as a diagnostic and prognostic biomarker and even a therapeutic target.
\end{abstract}

Keywords: LncRNA, SBF2-AS1, Cancers, Molecular mechanism, Biomarker, Therapy target

\section{Background}

The human genome consists of 2.86 billion nucleotide sequences, most of which can be transcribed, yet less than $2 \%$ of them possess translational potential [1-3]. Non-coding RNAs (ncRNA) make up the bulk of these transcripts, which can be divided into short ncRNAs represented by microRNAs (miRNAs) and long non-coding RNAs (lncRNAs) according to whether their length exceeds $200 \mathrm{nt}$ [4]. LncRNAs are roughly annotated as transcripts longer than $200 \mathrm{nt}$ and lack a positive-sense strand open reading frame longer than 100 amino acids [5]. Transcribed mainly by RNA pol II from intergenic or intron regions as well as gene-dense regions, lncRNAs are an extremely heterogeneous family, which is analogous to miRNA with $5^{\prime}$ capping and $3^{\prime}$ polyadenylation and splicing $[6,7]$. Due to the advancement of sequencing technology and the integration of algorithms in recent decades [8-10], sufficient evidence has proven that lncRNAs play an important biological role in different diseases [11-13].

*Correspondence: hanwd@zju.edu.cn; panhongming@zju.edu.cn

1 Department of Medical Oncology, Sir Run Run Shaw Hospital, College of Medicine, Zhejiang University, Hangzhou, China

Full list of author information is available at the end of the article
In terms of mechanism, existing studies have confirmed that lncRNAs act as signals, decoys, guides and scaffolds by interacting directly or indirectly with chromatin, proteins and other RNAs, and then exerting transcriptional and/or post-transcriptional regulatory activities in the nucleus and cytoplasm [14, 15]. The function of lncRNAs varies hinging on their subcellular localization [16]. Intranuclear lncRNAs are involved in the regulation of histone modifications, DNA methylation and chromatin remodeling, as well as interactions with chromatin modification complexes, transcription factors and proteins in the nucleus. Those located in the cytoplasm regulate genes mainly at the post-transcriptional and translational levels, including interactions with proteins in the cytoplasm, regulation of mRNA metabolism, and interactions with miRNAs as endogenous competitive RNAs (ceRNAs).

Cancer, as a global health problem, is the result of systemic or germline mutations in response to environmental factors; most of these mutations are located in regions with no coding potential, and most of their transcriptional products are lncRNAs [17, 18]. LncRNAs may act as oncogenes or antioncogenes, affecting tumorigenesis, progression, metastasis, and drug resistance by virtue of interactions with genes involved in the cell cycle, original author(s) and the source, provide a link to the Creative Commons licence, and indicate if changes were made. The images or other third party material in this article are included in the article's Creative Commons licence, unless indicated otherwise in a credit line to the material. If material is not included in the article's Creative Commons licence and your intended use is not permitted by statutory regulation or exceeds the permitted use, you will need to obtain permission directly from the copyright holder. To view a copy of this licence, visit http://creativecommons.org/licenses/by/4.0/. The Creative Commons Public Domain Dedication waiver (http://creativeco mmons.org/publicdomain/zero/1.0/) applies to the data made available in this article, unless otherwise stated in a credit line to the data. 
apoptosis, epithelial-mesenchymal transition (EMT), immunological response, phenotypic transformation, or other pluripotencies [19-24].

SET binding factor 2-antisense strand 1 (SBF2-AS1) is transcribed from the antisense strand of the SBF2 gene, which encodes myotubularin-related protein 13 (MTMR13) [25, 26]. We obtained genomic information on SBF2-AS1 from the GeneCards database (https:// www.genecards.org/). SBF2-AS1 is a lncRNA that is 2708 nucleotides in length and located on chromosome 11p15.4 (chromosome 11: 9758268-9811335). This transcript is localized in the cytoplasm, cytoskeleton, nucleus and extracellular regions. SBF2-AS1 is aberrantly expressed in cancers and is involved in carcinogenesis and tumor progression. Herein, we comprehensively reviewed research progress among cancers on the underlying mechanism and clinical significance of SBF2-AS1. Moreover, these provide support for the potential of SBF2-AS1 as a biomarker to predict prognosis and, more importantly, as a therapeutic target.

\section{Expression characteristics and mechanism of upregulation of SBF2-AS1 expression in tumors} LncRNA SBF2-AS1 was first characterized in non-small lung cancer (NSCLC) [26]. By analyzing a published lncRNA micromatrix dataset for NSCLC, Lv et al. found aberrant expression of SBF2-AS1. Subsequently, realtime quantitative PCR (RT-qPCR) analysis was performed on tumor tissues and adjacent normal tissues respectively, and the researchers found that SBF2-AS1 expression levels showed an approximately fivefold elevation on average in tumor tissues (in 36/41 patients). Then, more studies delved into the expression profile of SBF2-AS1 among other cancers, including pancreatic cancer (PC) [27], hepatocellular carcinoma (HCC) [28, 29], colorectal cancer (CRC) [30], gastric cancer (GC) [31], esophageal squamous cell cancer(ESCC) [32-34], breast cancer (BC) [35], glioblastoma (GBM) [36, 37], and others [38-41]. All of these studies with one accord showed that SBF2-AS1 was highly expressed in tumor tissue. Furthermore, RNA-FISH identified SBF2-AS1 was predominantly clustered in the cytoplasm [32, 42-44], which corresponds to its primary molecular mechanism. Additionally, we visualized the nuclear/cytoplasmic expression levels of SBF2-AS1 among diverse cancer cells through IncATLAS analysis (Fig. 1).

Nuclear transcription factors possess importance in the regulation of gene transcription via binding to a particular area of the promoter. It was shown that transcription factors are engaged in the upregulation of SBF2-AS1 expression. $\mathrm{Yu}$ et al. [36] found that the transcription factor nuclear factor of activated T-cells5(NFAT5), an aberrantly expressed transcription factor in tumors, can bind to the SBF2-AS1 promoter region at three presumptive sites through analyzing the JASPAR database, followed by PCR amplification and chromatin immunoprecipitation assays (ChIP) in glioblastoma cells. Finally, NFAT5 was shown to bind to and activate the promoter of SBF2-AS1 at the -1453 to -1448 bp region. Another research in glioblastoma revealed that transcription factor ZEB1 binds to the SBF2-AS1 promoter at the -684 to -676 bp region to augment SBF2-AS1 expression [37]. Analogously, Wang et al. demonstrated that E2F1 binds the SF2-AS1 promoter at the -58 to -66 bp region, thus upregulating SBF2-AS1 expression levels [38].

\section{Clinical significance of SBF2-AS1 in cancers}

The expression of SBF2-AS1 is observably different between normal and tumor tissues, and it is significantly higher in tumor tissues. Kaplan-Meier survival analysis showed that patients in the high SBF2-AS1 expression group had worse overall survival (OS) than those with low SBF2-AS1 expression, except for those with clear cell renal cell carcinoma (ccRCC) (Table 1). In addition, univariate and multivariate regression analysis results indicated that SBF2-AS1 was an independent prognostic indicator of OS in multiple cancers [28, 45]. In LC tissues, clinicopathological characteristics that are associated with overexpression of SBF2-AS1 are larger tumor size, advanced tumor-node-metastasis (TNM) stage, more lymph node metastasis, distant metastasis, poor tissue type and poor histological differentiation [26, 42, 46, 47]. One study verified that the expression level of SBF2-AS1 is elevated in early-stage lung adenocarcinoma [48]. This finding suggested that early diagnosis of lung adenocarcinoma is possible, which is important in improving the prognosis of patients and prolonging patient survival. In HCC, SBF2-AS1 was notably correlated with lymph node metastasis, histologic grade, TNM stage, and vascular invasion. Likewise, the results of the analysis indicateed that a high level of SBF2-AS1 was linked to unfavorable clinical indices such as progressive TNM stages, distant metastasis and lymph node metastasis in certain cancers [27, 32, 35, 39, 44]. Briefly, SBF2-AS1 functions as an oncogene whose expression level is significantly correlated with undesirable clinicopathological features and poor OS, which bolsters up SBF2-AS1 as an excellent prognostic biomarker. Moreover, high expression of SBF2-AS1 supports its use as a diagnostic marker.

\section{Roles of SBF2-AS1 in diverse cancers}

Extensive evidence suggests that dysregulation of SBF2AS1 is pivotal in cancer cell proliferation, migration, invasion, apoptosis and EMT. Hereof, we elaborate the functions and underlying mechanisms of SBF2-AS1 in 


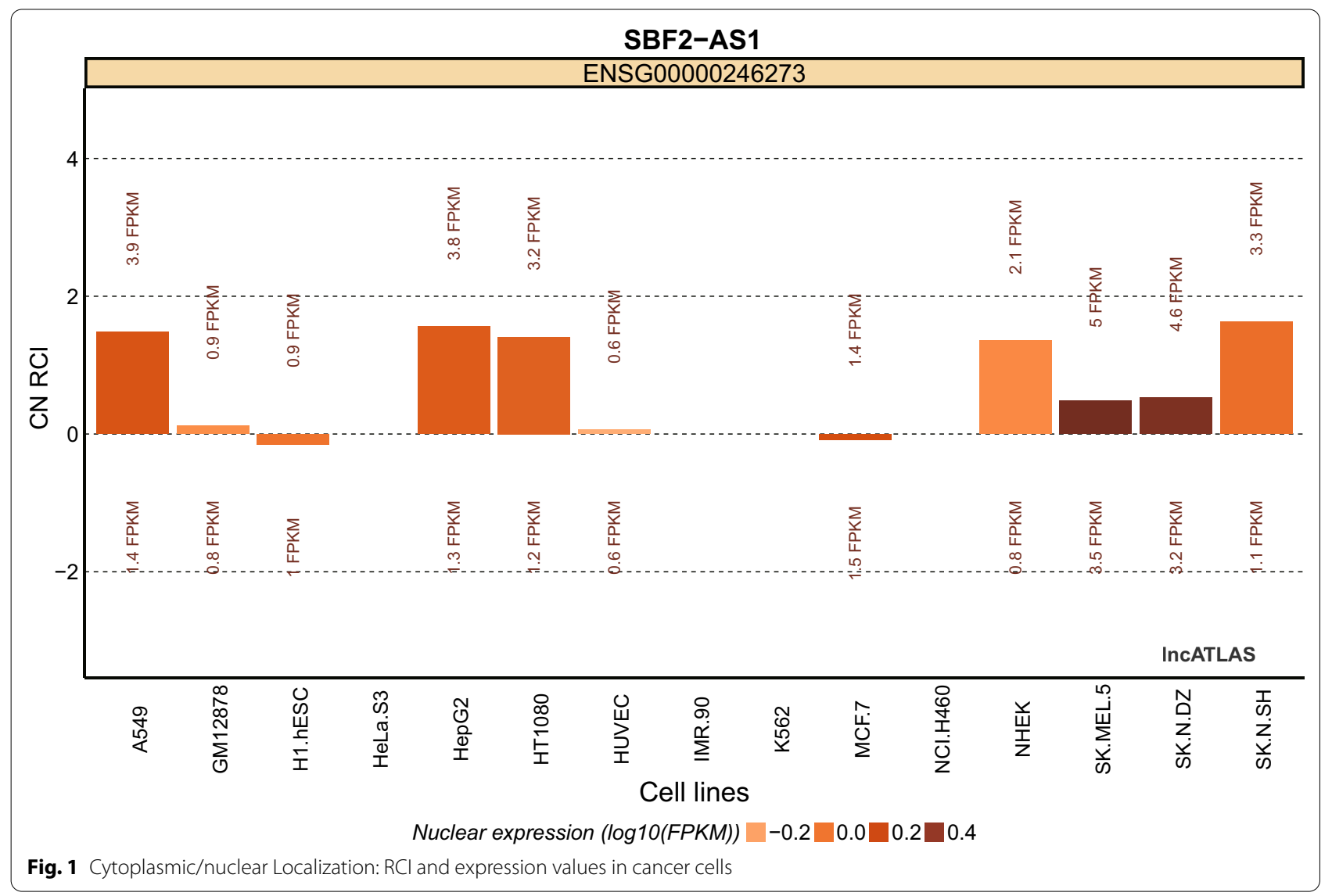

cancers (Table 2) and describe the mechanism of lung cancer and digestive system tumors (Figs. 2 and 3).

\section{Lung cancer}

As the second most prevalent and deadliest cancer worldwide, lung cancer (LC) is a health issue that needs to be addressed urgently. Non-small cell lung cancer (NSCLC) accounts for the majority of cases [49]. This disease is characterized by uncontrollable tumor proliferation, tumor heterogeneity, distant metastasis, tumor recurrence, and resistance to therapy. One choreographed in vitro experiment showed that SBF2-AS1 can bind to the subunit SUZ12, a core component of PRC2, through which it regulates enrichment of SUZ12 and trimethylation of histone 3 lysine 27 in the P21 promoter region. Loss-of-function experiment demonstrated that silencing of SBF2-AS1 remarkably upregulated P21 expression, thus suppressing NSCLC cell proliferation, migration and invasion [26].Additionally, one study manifested that SBF2-AS1 and a disintegrin and metalloproteinase 17 (ADAM17) share a functional miR response element, miR-338-3p, and SBF2-AS1 ultimately accelerates NSCLC progression through the ceRNA network
[50]. Upregulation of SBF2-AS1 expression regulated E2F1 expression through sponging and repressing miR338-3p or miR-362-3p in lung adenocarcinoma cells and contributed to cell proliferation [48]. Subsequently, Wang et al. proved that SBF2-AS1 directly binds miR-362-3p, further upregulating the expression level of growth factor receptor-bound protein 2 (GRB2) to promote NSCLC cell proliferation, migration and invasion [46]. Radiation tolerance is responsible for the poor response to radiotherapy. Yu et al. suggested that SBF2-AS1 plays an integral role in the radiosensitivity of NSCLC. Targeting the miR-302a/muscleblind-like splicing regulator 3 (MBNL3) signal axis, upregulated SBF2-AS1 expression distinctly strengthens NSCLC cell resistance to radiotherapy via reducing the expression of miR-302a [42]. Moreover, Qi et al. identified that SBF2-AS1 is linked to forkhead box protein M1 (FOXM1) via bioinformatics technology and Pearson correlation coefficients. Functionally, lncRNA SBF2-AS1 upregulates FOXM1 expression to inhibit apoptosis and promote proliferation of lung cancer cells [47]. Figure 1 summarizes the LncRNA SBF2-AS1 regulatory network in lung cancer. 
Table 1 Clinicopathologic significance of SBF2-AS1 in human cancers

\begin{tabular}{|c|c|c|c|c|}
\hline Cancer type & Expression & Sample numbers & Clinicopathologic features & Refs. \\
\hline Acute myeloid leukemia & Upregulated & 173 cancer samples 70 normal samples & Overall survival & [38] \\
\hline Breast cancer & Upregulated & 50 paired samples & $\begin{array}{l}\text { Lymph node metastasis, tumor size, clinical } \\
\text { stage }\end{array}$ & [35] \\
\hline \multirow[t]{6}{*}{ Lung cancer } & \multirow[t]{6}{*}{ Upregulated } & 50 paired samples & Overall survival & {$[47]$} \\
\hline & & 41 paired samples & Lymph node stage, TNM stage & {$[26]$} \\
\hline & & 174 paired samples & $\begin{array}{l}\text { Histological grade, lymph node metastasis, } \\
\text { overall survival }\end{array}$ & [124] \\
\hline & & 56 paired samples & $\begin{array}{l}\text { TNM stage, lymph node metastasis, Overall } \\
\text { survival }\end{array}$ & {$[50]$} \\
\hline & & 35 paired samples & $\begin{array}{l}\text { Age, tumor size, tumor tissue type, TNM stage, } \\
\text { Overall survival }\end{array}$ & [46] \\
\hline & & $\begin{array}{l}30 \text { normal samples } \\
30 \text { NSCLC samples } \\
96 \text { SCLC samples }\end{array}$ & $\begin{array}{l}\text { Extensive stage, tumor size }>3 \mathrm{~cm} \text {, lymph node } \\
\text { metastasis, distant metastasis, overall survival }\end{array}$ & [125] \\
\hline Osteosarcoma & Upregulated & 45 paired samples & Tumor size, distant metastasis, ennking stage & [44] \\
\hline Pancreatic cancer & Upregulated & 82 paired samples & $\begin{array}{l}\text { Degree of differentiation, TNM stage, lymph } \\
\text { Node metastasis }\end{array}$ & [27] \\
\hline Cervical cancer & Upregulated & 66 paired & $\begin{array}{l}\text { FIGO }^{\mathrm{a}} \text { stage, lymph node metastasis, overall } \\
\text { survival }\end{array}$ & [39] \\
\hline Colorectal cancer & Upregulated & $\begin{array}{l}61 \text { cancer samples } \\
29 \text { normal samples }\end{array}$ & TNM stages, survival rate & [30] \\
\hline Papillary thyroid cancer & Upregulated & 73 tumor samples (37 high and 36 low) & Overall survival & {$[40]$} \\
\hline \multirow[t]{2}{*}{ Glioblastoma } & \multirow[t]{2}{*}{ Upregulated } & $\begin{array}{l}47 \text { tumor samples } \\
5 \text { normal samples }\end{array}$ & Pathological grade & [36] \\
\hline & & $\begin{array}{l}20 \text { primary samples } \\
20 \text { recurrent samples }\end{array}$ & Overall survival & {$[37]$} \\
\hline Clear cell renal cell carcinoma & Upregulated & 46 paired & - & [41] \\
\hline \multirow[t]{2}{*}{ Hepatocellular carcinoma } & \multirow[t]{2}{*}{ Upregulated } & 184 paired samples & $\begin{array}{l}\text { Lymph node metastasis, histologic grade, TNM } \\
\text { stage, overall survival }\end{array}$ & [28] \\
\hline & & 134 paired samples & Vein invasion, TNM stage, overall survival rate & [29] \\
\hline Gastric cancer & Upregulated & 60 paired samples & TNM stage, overall survival & {$[31]$} \\
\hline \multirow[t]{3}{*}{ Esophageal squamous cell carcinoma } & \multirow[t]{3}{*}{ Upregulated } & 51 paired samples & $\begin{array}{l}\text { Smoking and drinking history, tumor size, TNM } \\
\text { stages, survival rate }\end{array}$ & [32] \\
\hline & & $\begin{array}{l}50 \text { tumor samples } \\
15 \text { normal samples }\end{array}$ & Survival rate & [33] \\
\hline & & 50 paired samples & Tumor size, survival rate & [34] \\
\hline
\end{tabular}

${ }^{a}$ International federation of gynecology and obstetrics

\section{Hepatocellular carcinoma}

Accounting for approximately $90 \%$ of total primary liver cancers, hepatocellular carcinoma (HCC) is a challenging disease worldwide with a dismal OS, which may be explained by its strong invasiveness and high recurrence rate [51, 52]. EMT, involved in different diseases, including cancers, refers to epithelial to mesenchymal cell transformation, through which cells are able to metastasize and invade [53]. Furthermore, diversified lncRNAs have been verified to modulate the EMT pathway in hepatocellular carcinoma [29, 54, 55]. Functional loss experiments observed that si-SBF2-AS1 markedly reduced the expression of $\mathrm{N}$-cadherin and vimentin, but slightly restored the expression of E-cadherin, thereby attenuating the invasiveness and metastasis of $\mathrm{HCC}$ cells [56]. Consistent with previous studies, SBF2-AS1 served as a ceRNA to regulate the miR-140-5p/transforming growth factor beta receptor 1(TGFBR1) axis and thus promoted HCC cell EMT, cell proliferation, migration and invasion [28]. Besides, Zhou et al. indicated that SBF2-AS1 and secretory carrier membrane protein 3 (SCAMP3) levels were obviously upregulated in HCC. Combined with miR-145-5p, which is distinctly decreased, SBF2-AS1 and SCAMP3 form a regulatory network involved in the progression of $\mathrm{HCC}$ via bioinformatics analysis. However, further experimental attestation is required to clarify the mechanism of ceRNA [57]. 
Table 2 Expression pattern and biological functions of SBF2-AS1 in human cancers

\begin{tabular}{|c|c|c|c|c|c|}
\hline Cancer type & Expression & Biological Function & Related genes & Roles & Refs \\
\hline Acute myeloid leukemia & Upregulated & Proliferation, Cell cycle, Apoptosis & miR-188-5p/ZFP91 & Oncogene & {$[38]$} \\
\hline Breast cancer & Upregulated & $\begin{array}{l}\text { Proliferation, cell cycle, invasion, migra- } \\
\text { tion, apoptosis }\end{array}$ & miR-143/RRS1 & Oncogene & {$[35]$} \\
\hline \multirow[t]{6}{*}{ Lung cancer } & Upregulated & $\begin{array}{l}\text { Promote cell proliferation, invasion, } \\
\text { migration }\end{array}$ & SUZ12, p21, Cyclin D1 & Oncogene & {$[26]$} \\
\hline & Upregulated & $\begin{array}{l}\text { Enhance radiotherapy resistance } \\
\text { (promote cell proliferation, inhibit } \\
\text { apoptosis) }\end{array}$ & miR-302a/MBNL3 & Oncogene & {$[42]$} \\
\hline & Upregulated & $\begin{array}{l}\text { Promote cell proliferation, invasion and } \\
\text { migration }\end{array}$ & miR-338-3p/ADAM17 & Oncogene & {$[50]$} \\
\hline & Upregulated & $\begin{array}{l}\text { Promote cell proliferation, invasion, } \\
\text { migration }\end{array}$ & E2F1/SBF2-AS1/miR-362-3p/GRB2 & Oncogene & {$[46]$} \\
\hline & Upregulated & Promote cell cycle and cell proliferation & miR-338-3p 、 miR-362-3p/E2F1 & Oncogene & {$[48]$} \\
\hline & Upregulated & $\begin{array}{l}\text { Promote cell proliferation, inhibit } \\
\text { apoptosis }\end{array}$ & FOXM1 & Oncogene & {$[47]$} \\
\hline Osteosarcoma & Upregulated & Proliferation, invasion, migration & miR-30a/FOXA1 & Oncogene & {$[44]$} \\
\hline \multirow[t]{2}{*}{ Pancreatic cancer } & Upregulated & $\begin{array}{l}\text { Promote cell proliferation, invasion, } \\
\text { migration and EMT, inhibit apoptosis }\end{array}$ & miR-142-3p/TWF1 & Oncogene & {$[27]$} \\
\hline & Upregulated & $\begin{array}{l}\text { Promote cell proliferation, invasion and } \\
\text { migration, inhibit apoptosis }\end{array}$ & miR-122-5p/XIAP & Oncogene & {$[43]$} \\
\hline Cervical cancer & Upregulated & Proliferation, cell cycle, apoptosis & miR-361-5p/FOXM1 & Oncogene & {$[39]$} \\
\hline Colorectal cancer & Upregulated & Proliferation, invasion, migration & miR-619-5p/HDAC3 & Oncogene & {$[30]$} \\
\hline Papillary thyroid cancer & Upregulated & $\begin{array}{l}\text { Proliferation, cell cycle,invasion, apop- } \\
\text { tosis }\end{array}$ & miR-431-5p/CDK14 & Oncogene & {$[40]$} \\
\hline \multirow[t]{2}{*}{ Glioblastoma } & Upregulated & $\begin{array}{l}\text { Reduce temozolomide sensitivity, pro- } \\
\text { mote tumor cell DNA repair }\end{array}$ & Z1B1/SBF2-AS1/miR-151-3p/XRCC4 & Oncogene & {$[37]$} \\
\hline & Upregulated & $\begin{array}{l}\text { Promote angiogenesis (enhance } \\
\text { endothelial cells viability, migration } \\
\text { and tube formation) }\end{array}$ & NFAT5/miR-338-3p/EGFL7/ERK & Oncogene & {$[36]$} \\
\hline Clear cell renal cell carcinoma & Upregulated & $\begin{array}{l}\text { Proliferation, invasion, migration, } \\
\text { apoptosis }\end{array}$ & miR-338-3p/ETS1 & Oncogene & {$[41]$} \\
\hline \multirow[t]{3}{*}{ Hepatocellular carcinoma } & Upregulated & $\begin{array}{l}\text { Promote cell proliferation, invasion, } \\
\text { migration and EMT }\end{array}$ & miR-140-5p/TGFBR1 & Oncogene & {$[28]$} \\
\hline & Upregulated & Promote cell migration and invasion & miR-145-5p/SCAMP3 & Oncogene & {$[57]$} \\
\hline & Upregulated & $\begin{array}{l}\text { Promote cell proliferation, invasion, } \\
\text { migration and EMT }\end{array}$ & $\mathrm{N}$-cadherin, vimentin & Oncogene & {$[29]$} \\
\hline Gastric cancer & Upregulated & Proliferation, invasion, migration & miR-545/EMS1 & Oncogene & {$[31]$} \\
\hline \multirow[t]{3}{*}{ Esophageal squamous cell carcinoma } & Upregulated & $\begin{array}{l}\text { Promote cell proliferation, invasion, } \\
\text { migration and EMT, inhibit apoptosis }\end{array}$ & miR-494/PFN2 & Oncogene & {$[33]$} \\
\hline & Upregulated & $\begin{array}{l}\text { Promote cell proliferation and inhibit } \\
\text { apoptosis }\end{array}$ & miR-338-3p/miR-362-3p/E2F1 & Oncogene & {$[34]$} \\
\hline & Upregulated & $\begin{array}{l}\text { Promote cell proliferation, invasion and } \\
\text { migration }\end{array}$ & CDKN1A & Oncogene & {$[32]$} \\
\hline
\end{tabular}

\section{Esophageal squamous cell carcinoma}

Esophageal squamous cell carcinoma (ESCC) accounts for $90 \%$ of esophageal cancers and has a high incidence in Asia. Despite advancements in diagnostic and therapeutic methods in recent years, the 5-year survival rate remains at approximately $15 \%[58,59]$. Several studies have indicated that SBF2-AS1 expression is increased, consequently facilitating ESCC cell proliferation, migration and invasion [32]. Functional experiments have shown that silencing SBF2-AS1 upregulates cyclindependent kinase inhibitor 1A (CDKN1A) expression in ESCC, affceting cell cycle arrest and thereby restraining the proliferative ability of ESCC cells via arresting them at the G2 phase [32]. Furthermore, SBF2-AS1 directly inhibits miR-494, resulting in the increased expression of profilin 2 (PFN2) and accelerated tumor progression [33]. Zha et al. verified that SBF2-AS1 and miR-338-3P or miR-362-3p inhibit each other in ESCC cells, and 


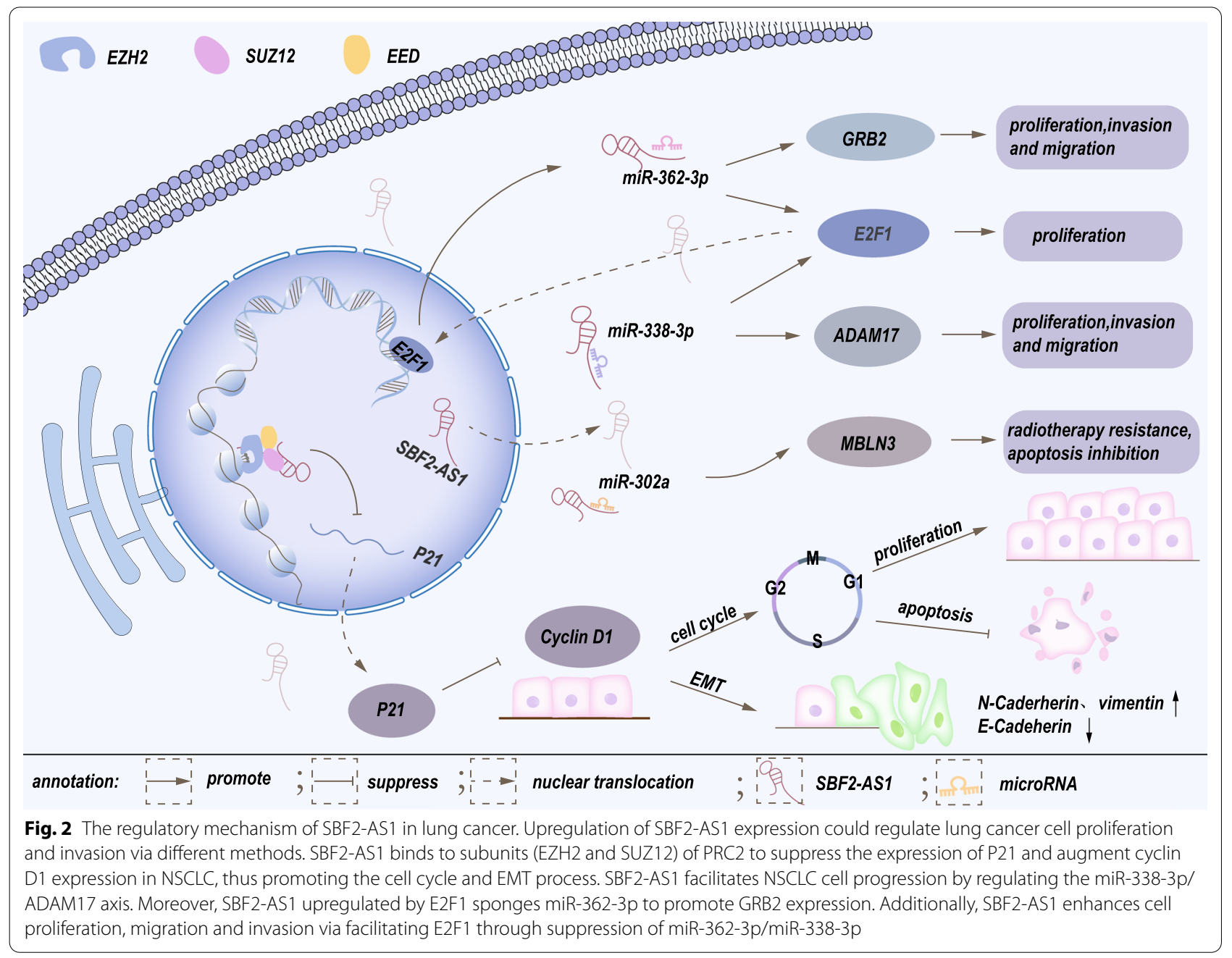

emphasized that overexpression of SBF2-AS1 and E2F1 is involved in tumor development and apoptosis [45].

\section{Pancreatic cancer}

Pancreatic cancer (PC) is a fatal malignancy worldwide [49]. For most PC cases, the 5-year survival rate does not exceed $10 \%$, due to its asymptomatic characteristics $[60,61]$. Drug resistance in pancreatic cancer also contributes to low survival rates in PC. Studies have shown that SBF2-AS1 expression is remarkably increased in PC cell lines $[27,43]$. Besides, Hua et al. detected a noticeable increase in the expression level of SBF2-AS1 and twinfilin-1 (TWF1) in gemcitabine-resistant PC cells, while miR-142-3p expression was inversely downregulated. Deficiency in SBF2-AS1 expression regained the sensitivity of gemcitabine-resistant PC cells via repressing cell proliferation, migration, invasion, and EMT [27]. Both M2 macrophages and exosomes have been shown to be involved in certain phases during progression of tumors or drug resistance [62-64]. One study verified that exosomal lncRNA SBF2-AS1, which is derived from M2 macrophages of pancreatic cancer, regulates the level of X-linked inhibitor of apoptosis protein (XIAP) expression by integrating with miR-122-5p. Restricting the expression of SBF2-AS1 significantly elevated miR122-5p level and inhibited XIAP expression, further inhibiting cell multiplication, and quenching invasiveness and metastasis in PC cells [43].

\section{Colorectal cancer}

Colorectal cancer (CRC) possesses high morbidity and mortality rates on a global scale [49]. SBF2-AS1, as an oncogene, was identified to be overexpressed in CRC cell lines by Chen et al. In vitro experimental results showed that SBF2-AS1 positively regulates the expression of histone deacetylase 3 (HDAC3) in CRC cells via acting as a "sponge" of miR-619-5p and inhibiting its expression [30]. HDAC3, an essential subunit of the nucleosome remodeling deacetylase of the chromatin remodeling complex, has been certified to act as an oncogene in a 


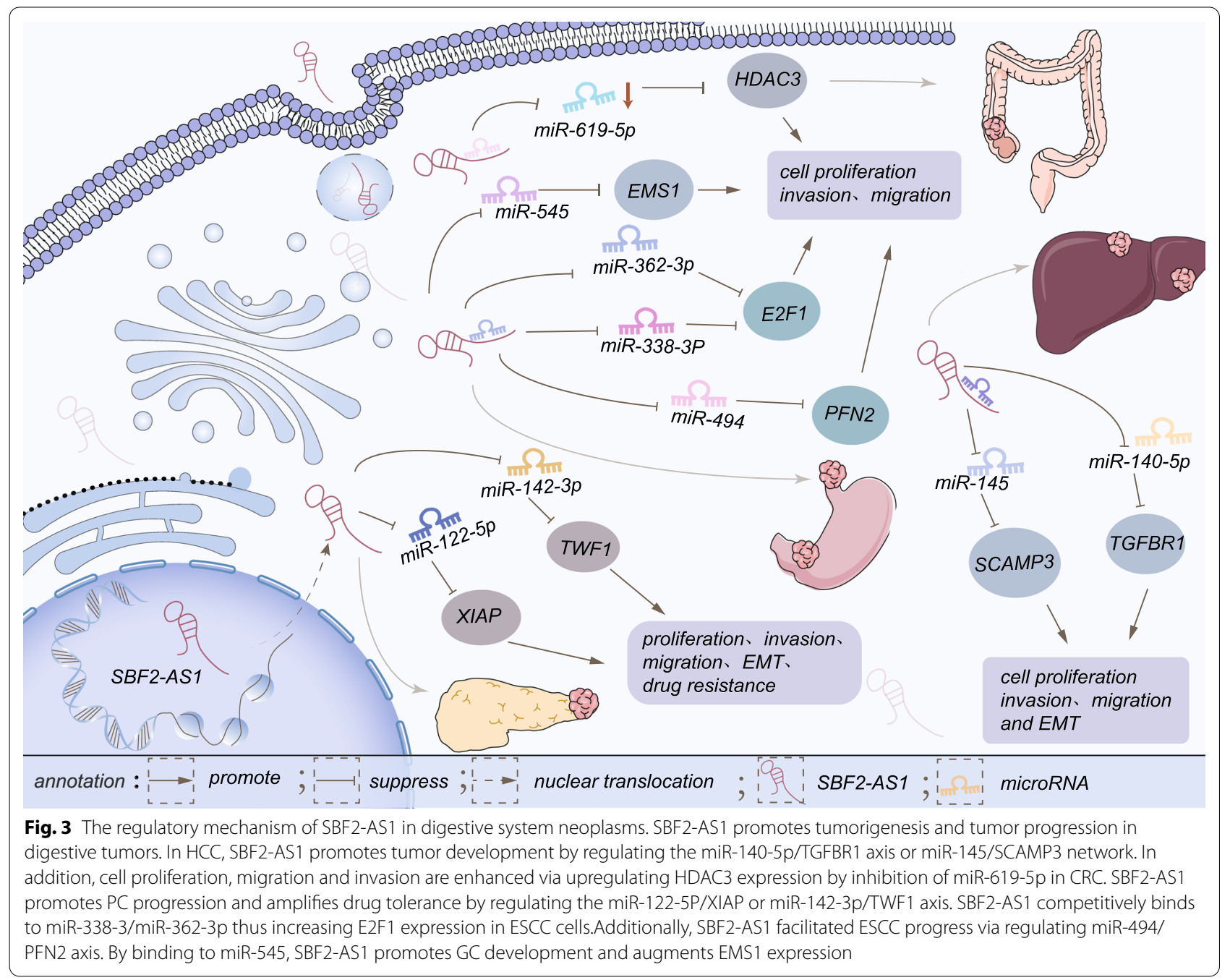

wide range of tumors [65-67]. Functionally, upregulation of SBF2-AS1 expression can enhance HDAC3, therefore promoting proliferation, metastasis and invasiveness of CRC cells [30].

\section{Gastric cancer}

Gastric cancer (GC), as a gastrointestinal tumor, is a malignancy that involves oncogenic activation, inactivation of tumor suppressor genes and aberrant protein expression [68-70]. He et al. indicated that SBF2-AS1 expression is significant increased in GC cell lines and plays a crucial role in tumor development. Forced upregulated SBF2-AS1 expression results in competitive binding of miR-545 through the ceRNA mechanism, thus increasing the expression of excess microsporocytes 1 (EMS1) and repressing miR-545 expression to facilitate GC cell growth and metastasis [31].

\section{Glioblastoma}

Glioblastoma (GBM) is the most common primary malignant tumor of the brain, with invasive clinical characteristics and a frightening lethality rate [71, 72]. Even under a comprehensive treatment strategy that includes surgical resection, chemotherapy based on temozolomide (TMZ) and adjuvant radiotherapy, the recurrence of glioma is inevitable, resulting in a 3-year survival rate $<10 \%$ [73]. Glioblastoma, a highly vascularized tumor, has high degree of growth malignancy and depends on the formation of new blood vessels [74]. Previous studies have demonstrated that lncRNAs are involved in angiogenesis in glioblastoma [75, 76]. Yu et al. revealed that nuclear factor of activated T cells 5 (NFAT5) enhanced SBF2-AS1 expression at the transcriptional phase.Thereafter, SBF2-AS1 functions as a ceRNA, sponges miR338-3p and alleviates the repressive effect on EGF like 
domain multiple 7 (EGFL7) at the post-transcriptional level, which stimulates endothelial cell activity, migration and tube formation. Further experiments demonstrated that EGFL7 exerts a potent angiogenic role through activating the ERK pathway [36]. In addition, transcription factor zinc finger E-box binding homeobox 1 (ZEB1) upregulates the level of X-ray repair cross complementing 4 (XRCC4) expression via the SBF2-AS1/miR-151-3p axis to enhance resistance to temozolomide in glioma cell lines. Highly expressed exosomal SBF2-AS1 was also shown to promote TMZ resistance in GBM cells in vivo [37].

\section{Cervical cancer}

Cervical cancer (CC) is a prevalent gynecologic malignant tumor [49]. Even with advances in treatment, the five-year survival rate for CC remains frustratingly low, principally attributed to tumor metastasis and recurrence [77, 78]. Gao et al. indicated that SBF2-AS1 expression was prominently increased in CC cells and positively correlated with FOXM1 expression because SBF2-AS1, as ceRNA binding to miR-361-5p, mitigated the suppressive effect of miR-361-5p on FOXM1. Gain-of-function experiments verified that upregulation of SBF2-AS1 expression enhances cell proliferation, and inhibits apoptosis of CC cells [39].

\section{Acute myeloid leukemia}

Acute myeloid leukemia (AML) is a malignant disease characterized by unregulated clonal propagation, abnormal infiltration and poor differentiation of immature myeloblasts of the hematologic system [79]. AML is a heterogeneous malignancy that is accompanied by cytogenetic changes, various biological features and molecular abnormalities [80, 81]. Dysregulation of lncRNAs is one of the genetic alterations [82, 83]. SBF2-AS1 was identified to be elevated in AML cells, and contributed to AML development via triggering cell cycle arrest and apoptosis. Further experiments indicated that SBF2AS1 functions as a ceRNA to alter the expression level of zinc finger protein 91 (ZFP91) by suppressing the expression of miR-188-5p [38].

\section{Breast cancer}

Breast cancer (BC) is the most common malignant tumor among global population and has a high mortality rate second to that of lung cancer [49]. Although there are various treatment options for breast cancer, choosing an appropriate therapy method for highly invasive and metastatic cases is still a major challenge. Previous studies have suggested that IncRNAs may offer new treatment targets for breast cancer patients [84-86]. Xia et al. proved that SBF2-AS1 expression and ralstonia solanacearum 1 (RRS1) expression are positively correlated. SBF2-AS1 has been proven to sequester miR-143 and subsequently increase the expression of RRS1 in BC cells, thereby repressing $\mathrm{BC}$ cell apoptosis and promoting cell proliferation, migration and invasion [35].

\section{Osteosarcoma}

Osteosarcoma is a malignant bone tumor and one of the most common sarcomas [87]. This malignancy originates from primitive osteogenic mesenchymal cells and occurs mostly in children, adolescents and young people. Multiple alternative strategies developed in the past several decades have not succeeded in improving the prognosis of patients with osteosarcoma [88]. Recently, scholars have focused on SBF2-AS1 as a therapeutic target in osteosarcoma. A study indicated that the level of SBF2-AS1 is remarkably elevated, and this molecule positively regulates forkhead box A1 (FOXA1) expression via sponging miR-30a and suppressing the expression of miR-30a in osteosarcoma cells, significantly affecting biological processes, such as cell multiplication, invasion, migration and apoptosis [44].

\section{Papillary thyroid cancer}

As a prevalent endocrine-system malignant neoplasm, papillary thyroid cancer (PTC) accounts for the majority of thyroid cancer [89]. The biological characteristics of PTC are highly diverse, ranging from nonprogressive to invasive metastatic carcinoma. Although there are various treatment modalities available for papillary thyroid cancer, researchers are still searching for an optimal treatment $[90,91]$. Wen et al. found that SBF2-AS1 expression increased distinctly in PTC cells and strongly affected tumor progression. Functionally, downregulation of SBF2-AS1 expression decreased cyclin-dependent kinase 14(CDK14) expression and conversely increased miR-431-5p expression, which suppresses PTC cell viability and promotes apoptosis [40].

\section{Clear cell renal cell carcinoma}

Clear cell renal cell carcinoma (ccRCC) as the dominant type of kidney cancer, has the highest fatality rate compared to other types [92]. It was reported that SBF2-AS1, serving as a molecular sponge of miR-338-3p, competitively binds to miR-338-3p and inhibits its expression, thus enhancing ETS1 expression in ccRCC cells. Further functional studies showed that decreased expression of SBF2-AS1 restrains the proliferation and invasiveness of ccRCC cells and triggers apoptosis and autophagy by blocking ETS1 and upregulating miR-338-3p expression [41]. 


\section{Regulatory mechanism of downstream genes by SBF2-AS1}

Interaction with RNA (as a ceRNA)

The ceRNA hypothesis reveals a mechanism of RNA interactions that has been useful in explaining abnormal transcriptome changes. The hypothesis presumes that ceRNAs, including circRNAs, lncRNAs, and mRNAs, regulate downstream gene expression by competitively binding microRNAs. The novel lncRNA SBF2-AS1, with a length of $2708 \mathrm{bp}$, primarily localized in the cytoplasm, possesses many latent miRNA binding sites and exerts an effect on malignant biological processes principally through a ceRNA mechanism. It was also observed that the expression level of SBF2-AS1 was mostly higher than or equivalent to that of miR-338-3p, which sustains its roles in cancers.

For instance, Yang et al. [41] identified that SBF2-AS1 was located in the cytoplasm by FISH, followed by a dual luciferase reporter gene assay, which showed that the luciferase activity of the vector carrying SBF2-AS1-WT was markedly weakened in 768-O cells by miR-338-3p mimics. Later, an RNA binding protein immunoprecipitation (RIP) assay was applied to verify that both miR-338-3p and SBF2-AS1 were enriched in beads containing Ago2. To further illuminate the interaction between SBF2-AS1 and miR-338-3p, through RNA pull-down, the researchers detected a noticeable rise in the concentration of SBF2-AS1 in the bio-miR-338-WT group. By RT-qPCR assays, elevated miR-338-3p expression was detected after treatment with either miR-338-3p mimics or si-SBF2-AS1. In contrast, the miR-338-3p expression level was significantly decreased after using PCDNA-SBF2-AS1 or miR-338-3p inhibitor. From this, it can be concluded that SBF2-AS1 functions as a ceRNA by sponging miR-338-3p and negatively regulates its expression in clear cell renal cell cancer. SBF2-AS1 was also observed to interact with miR-338-3p similarly in NSCLC and glioblastoma.

Based on the results of the dual luciferase reporter gene assay, Ago2-RIP assay, RNA pull-down and RT-qPCR, SBF2-AS1 can serve as a sponge that competitively binds to miR-122-5p, miR-362-3p, miR-188-5p, miR-30a, miR142-3p, miR-361-5p, miR-151-3p and so on (Table 2), thus regulating biological processes in tumor cells. Bioinformatics analysis is increasingly valued by researchers as an aid to tumor studies. In particular, these methods have shown potential in the analysis of RNA-RNA interactions. By performing bioinformatic analysis, Zhou et al. identified miR-145 binding site of SBF2-AS1; however, further experiments are needed to verify whether the putative binding site is functional.

\section{Interaction with DNA}

SBF2-AS1 engages in methylation modification of genes to regulate their expression at the DNA level [26, 32]. Polycomb repressive complex 2 (PRC2) is a chromatinassociated methyltransferase involved in catalyzing the methylation of lysine 27 on histone H3 (H3K27) [93], which is an important regulator of tumor development and progression. Previous studies have demonstrated that lncRNAs may function in regulating PRC2 recruitment [94] or directly bind to its subunits, such as SUZ12 [95], thus regulating epigenetic modification. SBF2-AS1 can recruit and then bind SUZ12 and EZH2 of PRC2, then enrich PRC2 in the promoter region of P21, thus inactivating $\mathrm{P} 21$, which arrests the cell cycle at $\mathrm{S}$ phase to promote indefinite proliferation in NSCLC as well as ESCC.

\section{Molecular interference between SBF2-AS1 and the signal pathway}

SBF2-AS1 mainly acts as a ceRNAs to regulate downstream genes of miRNAs, many of which are involved in signaling pathways. For example, LncRNA SBF2-AS1 can regulate the ERK signaling pathway [36]. Researches have demonstrated that ERKs and their signaling pathways play a role in mediating and amplifying signals during tumor invasion and metastasis by regulating cell proliferation, differentiation and viability [96]. Overexpression of SBF2-AS1 can upregulate EGFL7 expression and thus significantly increase the expression of p-ERK, which is an important member of the MAPK/ERK signaling pathway and one of the key components to initiate the signal cascade [97]. The ERK signaling pathway proteins include RAS, RAF, MEK, MAPK, STAT3, p90rsk, cFos, c-Myc and n-Myc. However, the specific molecules through which SBF2-AS1 exerts its oncogenic effects need to be further investigated.

In addition, SBF2-AS1 show crosstalk with other signaling pathway members; for example, GRB2, a key adapter protein that activates the Ras/Erk pathway, is involved in EGFR-mediated signaling transduction [98]. Upregulated Grb2 expression correlates with p-c-Raf, p-Mek1/2 and p-Erk1/2, which are pivotal members of the Ras/Erk pathway [99]. Another example is HDAC3, which is increased in CRC by overexpression of SBF2AS1and is reported to be involved in TGF- $\beta$ signaling pathway [100]. HDAC3 is positively correlated with the regulation of TGF- $\beta 1, p$-smad2, and p-smad3, all of which are TGF- $\beta$-related proteins. Multiple regulatory pathways exist in the same tumor, even containing the same molecules of action, but the interactions and relationships between SBF2-AS1 and regulatory pathways still require further molecular experimental studies. 


\section{SBF2-AS1 as a therapeutic target for cancers}

Since lncRNA expression exhibits striking tissue specificity compared with mRNA expression [101], an increasing number of studies have shown that targeting lncRNAs is a desirable therapeutic approach [102]. As previously noted, lncRNA SBF2-AS1, as a novel oncogene, plays a critical role in tumor progression and is associated with poor OS. More importantly, the core role of SBF2-AS1 is a shared feature of plentiful tumors. All the above findings suggest that silencing SBF2-AS1 is an effective therapeutic strategy to inhibit tumor growth. Besides, SBF2-AS1 binds to miRNAs as a ceRNA and abolishes the inhibitory effect on downstream target genes. Thus, upregulation of miRNA expression to quell the action of downstream target genes can be regarded as a therapeutic strategy. In recent decades, RNA-based anticancer therapies have gradually moved from concept to reality [103-105]. Compared to targeting proteins, lncRNAtargeting drugs exhibit preferabletherapeutic potential because they bypass the pleiotropic effects of many current therapeutic modalities [106]. Current prevalent strategies for lncRNA targeting include antisense oligonucleotides (ASOs), clustered regularly interspaced short palindromic repeats/CAS9 (CRISPR/CAS9), and small molecules [107, 108]. ASOs, chemically synthesized short fragment oligonucleotides, bind to RNA through Watson-crick base pairing, thereby altering gene expression [109]. Currently, ASOs targeting different mRNAs have shown clinical benefits for specific diseases [110]. These molecules show effective targeting of lncRNAs in the preclinical stage [111-113]. One study noted that ASOs targeting and silencing MALAT1 contributed to moderate tumor proliferation in the MMTV (mouse mammary tumor virus)-PYMT mouse breast cancer model, along with remarkable differentiation into cystic tumors and a decrease in lung metastasis [113]. Based on these findings, we believe that the ASO product targeting SBF2-AS1 is promising for tumor therapy in the future. CRISPR/Cas9, a gene editing technology, targets the region of the gene promoter to silence transcription and has been used in cancer cells and animal cancer models [114-116]. A choreographed animal study of gastric cancer revealed that targeting lncRNA GMAN by CRISPR-CAS9 inhibited tumor metastasis and improved survival rates in mice [115]. By this means, we were able to achieve silencing the transcription of SBF2-AS1 expression loci. Notably, small molecules have recently become a focus of research by virtue of their nonimmunogenic nature, systemic delivery and highly plastic physicochemical structure [117]. An RNA-targeted small molecule, risdilasm, was approved for the treatment of spinal muscular atrophy in 2020 in the USA [118]. As small molecules targeting lncRNAs have not yet been druggable, studies have increasingly focused on breaking through this dilemma [119-121]. YK-4-279, a novel man-made molecule, displays a strong suppressive impact on Ewing sarcoma cells via regulating lncRNA HULC (highly upregulated in liver cancer) [121]. By drawing on these experiences, we may be able to design small molecules that precisely target SBF2-AS1 based on its secondary structure and mode of action for clinical treatment. In conclusion, these modalities are not yet mature and lncRNA-based therapeutics are in the preliminary period of development, requiring more intensive and in-depth research as well as clinical trials to support them and accelerate their development.

\section{Discussion}

In this review, we present a comprehensive analysis of all the studies on SBF2-AS1 to date, describing the clinical studies as well as molecular mechanisms and biological functions of SBF2-AS1 in terms of tumor classification, followed by an in-depth discussion of the molecules that interact with SBF2-AS1. The biological functions of SBF2-AS1 are mainly related to tumor proliferation, invasion, metastasis, EMT, angiogenesis, chemoresistance and radiosensitivity. The current clinical studies on SBF2AS1 are mainly concerned with intertissue variation in expression and correlation with some clinical features, which are not sufficient to support it as a diagnostic biomarker and indicate the need for more accurate, detailed and in-depth large clinical trials to confirm its role.

Current studies all suggest a consistent role for SBF2AS1 in tumors. LncRNA SBF2-AS1, which acts as an oncogene, is overexpressed in various tumor tissues and cells, including lung cancer, hepatocellular carcinoma, esophageal squamous cell carcinoma, breast cancer, ovarian cancer, cervical cancer, osteosarcoma, colorectal cancer, and pancreatic cancer. Moreover, studies have revealed that SBF2-AS1 expression is detected to be upregulated in exosomes, which is correlated with the sensitivity of GBM cells to temozolomide and with tumor progression in PC. In addition, SBF2-AS1 exerts an impact on drug resistance in $\mathrm{CRC}$ and radioresistance in NSCLC. Elevated levels of SBF2-AS1 reinforce the tolerance to radiotherapy in NSCLC. Upregulation of SBF2-AS1 expression in CRC is related to resistance to gemcitabine. In-depth clinical analysis showed that there exists an intimate connection between the expression level of SBF2-AS1 and the clinical features of patients. Upregulation of SBF2-AS1 expression predicted poor OS, and was associated with larger tumor size, advanced TNM stage, lymph node metastasis, and poorer pathological differentiation. Mechanistically, SBF2-AS1 
predominantly forms a ceRNA network with miRNAs and downstream genes to regulate tumor progression. There are different regulatory axes in the same tumor, such as enhancing ESCC cell proliferation through miR$188-5 \mathrm{p} / \mathrm{PFN} 2$ or interacting with $\mathrm{miR}-338-3 \mathrm{P} / \mathrm{miR}$ 362-3p to activate E2F1 expression. These phenomena may be mediated by the presence of several different miRNA binding sites in the SBF2-AS1 sequence. In addition, different tumors may activate different downstream genes through the same miRNA molecule, for example, in ccRCC, by sponging miR-338-3p and upregulating ETS1 expression or in NSCLC via activating ADAM17, thus promoting tumor proliferation, invasion and metastasis, which is due to the functional characteristics of miRNAs capable of regulating multiple downstream genes. These studies alone have not fully elucidated and strongly support the roles of SBF2-AS1 in cancers, and more experimental research is needed. More importantly, whether lncRNA SBF2-AS1 functions as a sponge of microRNAs should be carefully assayed in each case, and particularly the relative expression of the lncRNA and microRNAs should be quantified to make any conclusion. Furthermore, SBF2-AS1 may regulate the MAKP/ERK, the TGF- $\beta$ signaling pathways. The interactions between SBF2-AS1 and other signaling pathways require more meticulous experiments for confirmation. Regarding the upstream regulatory mechanism of SBF2-AS1, existing studies have confirmed that high expression of SBF2-AS1 is controlled by the transcription factors E2F1, ZEB1 and NFAT5 at the transcriptional level. Whether SBF2-AS1 is subject to epigenetic regulation and splicing is not yet known, and further researches are requisite to figure out.

\section{Perspectives}

The regulatory mechanisms of lncRNAs are diverse and complex. SBF2-AS1 has already been reported to promote cancer development, chemoresistance and radioresistance by interacting with RNA, DNA or crosstalk with molecules of various signal pathways. Molecular and clinical researches of SBF2-AS1 are still in their infancy, and SBF2-AS1 shows potential for future applications. First, directly or indirectly targeting SBF2-AS1 to suppress its expression through ASOs, CRISPR/ CAS9 or biological molecules may be a viable remedy for cancers as mentioned above, in the future, especially for some current refractory tumors. Secondly, considering the relationship between SBF2-AS1 and drug resistance, SBF2-AS1 provides a new entry point for research on therapeutic tolerance, which is favorable for further clarifying the mechanism of drug resistance from various aspects in cancers. Given this, we maintain that targeting SBF2-AS1 may be an adjunct to conventional drugs to extend the duration of the beneficial effects. However, further experimental studies should be implemented to clarify the detailed drug-resistance mechanisms. In addition to its potential as a therapeutic target, SBF2-AS1 was also detected at high levels in exosomes. Does this imply that SBF2-AS1 can be detected in body fluids (blood, cerebrospinal fluid, etc.) in addition to tissues with differential SBF2-AS1 expression? Therefore, subsequent studied could explore this issue, which will promote early identification of tumorigenesis and thus contribute to treatment at an early stage. Then, the signaling pathways involved in downstream genes of SBF2-AS1 and the interaction of SBF2-AS1 with downstream genes should be particularly refined and expanded, which could link this IncRNA to currently known pathways and then concretize the mechanisms regulating tumor development. Moreover, previous studies have revealed that lncRNAs can interact with proteins through multiple approaches, such as regulating mRNA splicing-associated proteins or protein modifications [122, 123]. However, the interaction between SBF2-AS1 and proteins requires further elucidation. Finally, the regulatory mechanisms and functions involved in SBF2-AS1 have been identified in vitro, indicating that these functions, such as the mechanism of metastasis and EMT, have not been confirmed. For confirmation, further studies conducted in a physiological setting are needed.

\section{Conclusions}

The role of lncRNAs in cancers known currently remains a tip of the iceberg, and future studies are required. This paper reviews SBF2-AS1 regulation of tumor cell proliferation, metastasis, invasion, angiogenesis, chemoresistance, radiosensitivity, and the cell cycle through interactions with different molecules (miRNA, DNA or signaling pathway molecules), indicating that SBF2-AS1 has promise in the future as a diagnostic and prognostic biomarker and a prospective therapeutic target for cancers.

\footnotetext{
Abbreviations

ncRNA: Noncoding RNAs; miRNAs: MicroRNAs; IncRNAs: Long noncoding RNAs; ceRNA: Competitive endogenous RNA; EMT: Epithelial-mesenchymal transition; SBF2-AS1: SET binding factor 2-antisense strand 1; MTMR13: Myotubularin-related protein 13; LC: Lung cancer; PC: Pancreatic cancer; HCC: Hepatocellular carcinoma; CRC: Colorectal cancer; GC: Gastric cancer; ESCC: Esophageal squamous cell cancer; BC: Breast cancer; GBM: Glioblastoma; OS: Overall survive; ccRCC: Clear cell renal cell carcinoma; TNM: Tumor-nodemetastasis; NSCLC: Non-small cell lung cancer; PRC2: Polycomb repressive complex 2; H3K27: Lysine 27 on histone H3; ADAM17: A disintegrin and metalloproteinase 17; GRB2: Growth factor receptor-bound protein 2; MBNL3: Muscleblind-like splicing regulator 3; FOXM1: Forkhead box protein M1; TGFBR1:Transforming growth factor beta receptor 1; SCAMP3: Secretory carrier membrane protein 3; CDKN1A: Cyclin-dependent kinase inhibitor 1A; PFN2: Profilin 2; TWF1: Twinfilin-1; XIAP: X-linked inhibitor of apoptosis protein; HDAC3: Histone deacetylase 3; EMS1: Excess microsporocytes 1; TMZ: Temozolomide; NFAT5: Nuclear factor of activated T cells 5; EGFL7: EGF like domain multiple 7; ZEB1: Zinc finger E-box binding homeobox 1; XRCC4: X-ray
} 
repair cross complementing 4; ZFP91: Zinc finger protein 91; RRS1: Ralstonia solanacearum 1; FOXA1: Forkhead box A1; CC: Cervical cancer; AML: Acute myeloid leukemia; PTC: Papillary thyroid cancer; CDK14: Cyclin-dependent kinase 14; ASOs: Antisense oligonucleotides; CRISPR/CAS9: Clustered regularly interspaced short palindromic repeats/CAS9; HULC: Highly upregulated in liver cancer; RIP: RNA Binding Protein Immunoprecipitation; RT-qPCR: Real Time quantitative PCR; MMTV: Mouse mammary tumor virus.

\section{Acknowledgements}

We acknowledge the support by the Zhejiang Medical Innovative Discipline Construction Project-2016.

\section{Authors' contributions}

Conceptualization: QL and JL. writing and editing: QL, RC, WH and HP. All authors contributed to the article. All authors read and approved the final manuscript.

\section{Funding}

No funding.

Availability of data and materials

All data are included in this article.

\section{Declarations}

\section{Ethics approval and consent to participate}

Not applicable.

\section{Consent for publication}

Not applicable.

\section{Competing interests}

The authors declare that they have no competing interests.

\section{Author details}

'Department of Medical Oncology, Sir Run Run Shaw Hospital, College of Medicine, Zhejiang University, Hangzhou, China. ${ }^{2}$ Department of Colorectal Surgery, Sir Run Run Shaw Hospital, College of Medicine, Zhejiang University, Hangzhou, China.

Received: 7 May 2021 Accepted: 29 July 2021

Published online: 09 August 2021

\section{References}

1. Uddin MN, Wang X. The landscape of long non-coding RNAs in tumor stroma. Life Sci. 2021;264: 118725

2. Dinger ME, Pang KC, Mercer TR, Mattick JS. Differentiating proteincoding and noncoding RNA: challenges and ambiguities. PLoS Comput Biol. 2008;4(11): e1000176.

3. International Human Genome Sequencing Consortium. Finishing the euchromatic sequence of the human genome. Nature. 2004;431(7011):931-45.

4. Kapranov P, Cheng J, Dike S, Nix DA, Duttagupta R, Willingham AT, Stadler PF, Hertel J, Hackermüller J, Hofacker IL, et al. RNA maps reveal new RNA classes and a possible function for pervasive transcription. Science. 2007;316(5830):1484-8.

5. Salviano-Silva A, Lobo-Alves SC, Almeida RC, Malheiros D, Petzl-Erler ML. Besides pathology: long non-coding RNA in cell and tissue homeostasis. Noncoding RNA. 2018. https://doi.org/10.3390/ncrna4010003.

6. Aprile M, Katopodi V, Leucci E, Costa V. LncRNAs in cancer: from garbage to junk. Cancers. 2020. https://doi.org/10.3390/cancers 12113220.

7. Ponting CP, Oliver PL, Reik W. Evolution and functions of long noncoding RNAs. Cell. 2009;136(4):629-41.

8. Mortazavi A, Williams BA, McCue K, Schaeffer L, Wold B. Mapping and quantifying mammalian transcriptomes by RNA-Seq. Nat Methods. 2008:5(7):621-8

9. Guttman M, Garber M, Levin JZ, Donaghey J, Robinson J, Adiconis X, Fan L, Koziol MJ, Gnirke A, Nusbaum C, et al. Ab initio reconstruction of cell type-specific transcriptomes in mouse reveals the conserved multiexonic structure of lincRNAs. Nat Biotechnol. 2010;28(5):503-10.

10. Wu Y, Zhang $\mathrm{K}$. Tools for the analysis of high-dimensional single-cell RNA sequencing data. Nat Rev Nephrol. 2020;16(7):408-21.

11. Batista PJ, Chang HY. Long noncoding RNAs: cellular address codes in development and disease. Cell. 2013;152(6):1298-307.

12. Peng WX, Koirala P, Mo YY. LncRNA-mediated regulation of cell signaling in cancer. Oncogene. 2017;36(41):5661-7.

13. Uchida S, Dimmeler S. Long noncoding RNAs in cardiovascular diseases. Circ Res. 2015;116(4):737-50.

14. Gibb EA, Brown CJ, Lam WL. The functional role of long non-coding RNA in human carcinomas. Mol Cancer. 2011;10:38.

15. Moran VA, Perera RJ, Khalil AM. Emerging functional and mechanistic paradigms of mammalian long non-coding RNAs. Nucleic Acids Res. 2012;40(14):6391-400.

16. Chen LL. Linking long noncoding RNA localization and function. Trends Biochem Sci. 2016;41(9):761-72.

17. Huarte M. The emerging role of IncRNAs in cancer. Nat Med. 2015;21(11):1253-61.

18. Maurano MT, Humbert R, Rynes E, Thurman RE, Haugen E, Wang $\mathrm{H}$, Reynolds AP, Sandstrom R, Qu H, Brody J, et al. Systematic localization of common disease-associated variation in regulatory DNA. Science. 2012;337(6099):1190-5.

19. Li J, Meng H, Bai Y, Wang K. Regulation of IncRNA and its role in cancer metastasis. Oncol Res. 2016;23(5):205-17.

20. Martínez-Barriocanal Á, Arango D, Dopeso H. PVT1 long non-coding RNA in gastrointestinal cancer. Front Oncol. 2020;10:38.

21. Huang D, Chen J, Yang L, Ouyang Q, Li J, Lao L, Zhao J, Liu J, Lu Y, Xing $Y$, et al. NKILA IncRNA promotes tumor immune evasion by sensitizing T cells to activation-induced cell death. Nat Immunol. 2018:19(10):1112-25.

22. Wei L, Sun J, Zhang N, Zheng Y, Wang X, Lv L, Liu J, Xu Y, Shen Y, Yang M. Noncoding RNAs in gastric cancer: implications for drug resistance. Mol Cancer. 2020;19(1):62.

23. Jin $\mathrm{KT}$, Yao JY, Fang XL, Di H, Ma YY. Roles of IncRNAs in cancer: focusing on angiogenesis. Life Sci. 2020;252: 117647.

24. Castro-Oropeza R, Melendez-Zajgla J, Maldonado V, Vazquez-Santillan $K$. The emerging role of IncRNAs in the regulation of cancer stem cells. Cell Oncol. 2018;41 (6):585-603.

25. Senderek J, Bergmann C, Weber S, Ketelsen UP, Schorle H, RudnikSchöneborn S, Büttner R, Buchheim E, Zerres K. Mutation of the SBF2 gene, encoding a novel member of the myotubularin family, in Charcot-Marie-Tooth neuropathy type 4B2/11 p15. Hum Mol Genet. 2003;12(3):349-56.

26. LV J, Qiu M, Xia W, Liu C, Xu Y, Wang J, Leng X, Huang S, Zhu R, Zhao $M$, et al. High expression of long non-coding RNA SBF2-AS1 promotes proliferation in non-small cell lung cancer. J Exp Clin Cancer Res. 2016;35:75

27. Hua YQ, Zhu YD, Xie GQ, Zhang K, Sheng J, Zhu ZF, Ning ZY, Chen H, Chen Z, Meng ZQ, et al. Long non-coding SBF2-AS1 acting as a competing endogenous RNA to sponge microRNA-142-3p to participate in gemcitabine resistance in pancreatic cancer via upregulating TWF1. Aging. 2019;11(20):8860-78.

28. LiY, Liu G, Li X, Dong H, Xiao W, Lu S. Long non-coding RNA SBF2-AS1 promotes hepatocellular carcinoma progression through regulation of miR-140-5p-TGFBR1 pathway. Biochem Biophys Res Commun. 2018;503(4):2826-32.

29. Li Y, Guo D, Ren M, Zhao Y, Wang X, Chen Y, Liu Y, Lu G, He S. Long non-coding RNA SNAI3-AS1 promotes the proliferation and metastasis of hepatocellular carcinoma by regulating the UPF1/Smad7 signalling pathway. J Cell Mol Med. 2019;23(9):6271-82.

30. Chen G, Gu Y, Han P, Li Z, Zhao JL, Gao MZ. Long noncoding RNA SBF2AS1 promotes colorectal cancer proliferation and invasion by inhibiting miR-619-5p activity and facilitating HDAC3 expression. J Cell Physiol. 2019;234(10):18688-96.

31. He M, Feng L, Qi L, Rao M, Zhu Y. Long noncoding RNASBF2-AS1 Promotes gastric cancer progression via regulating miR-545/EMS1 axis. Biomed Res Int. 2020;2020:6590303.

32. Chen R, Xia W, Wang X, Qiu M, Yin R, Wang S, Xi X, Wang J, Xu Y, Dong $G$, et al. Upregulated long non-coding RNA SBF2-AS1 promotes 
proliferation in esophageal squamous cell carcinoma. Oncol Lett. 2018;15(4):5071-80.

33. Zhang Q, Pan X, You D. Overexpression of long non-coding RNA SBF2AS1 promotes cell progression in esophageal squamous cell carcinoma (ESCC) by repressing miR-494 to up-regulate PFN2 expression. Biol Open. 2020. https://doi.org/10.1242/bio.048793.

34. Zha W, Li X, Tie X, Xing Y, Li H, Gao F, Ye T, Du W, Chen R, Liu Y. The molecular mechanisms of the long noncoding RNA SBF2-AS1 in regulating the proliferation of oesophageal squamous cell carcinoma. Sci Rep. 2021;11(1):805.

35. Xia W, Liu Y, Cheng T, Xu T, Dong M, Hu X. Down-regulated IncRNA SBF2-AS1 inhibits tumorigenesis and progression of breast cancer by sponging microRNA-143 and repressing RRS1. J Exp Clin Cancer Res. 2020;39(1):18

36. Yu H, Zheng J, Liu X, Xue Y, Shen S, Zhao L, Li Z, Liu Y. Transcription factor NFAT5 promotes glioblastoma cell-driven angiogenesis via SBF2-AS1/miR-338-3p-mediated EGFL7 expression change. Front Mol Neurosci. 2017;10:301

37. Zhang Z, Yin J, Lu C, Wei Y, Zeng A, You Y. Exosomal transfer of long noncoding RNA SBF2-AS1 enhances chemoresistance to temozolomide in glioblastoma. J Exp Clin Cancer Res. 2019;38(1):166.

38. Tian YJ, Wang YH, Xiao AJ, Li PL, Guo J, Wang TJ, Zhao DJ. Long noncoding RNA SBF2-AS1 act as a ceRNA to modulate cell proliferation via binding with miR-188-5p in acute myeloid leukemia. Artif Cells Nanomed Biotechnol. 2019;47(1):1730-7.

39. Gao F, Feng J, Yao H, Li Y, Xi J, Yang J. LncRNA SBF2-AS1 promotes the progression of cervical cancer by regulating miR-361-5p/FOXM1 axis. Artif Cells Nanomed Biotechnol. 2019;47(1):776-82.

40. Wen HL, Xu ZM, Wen D, Lin SY, Liang Y, Xie JP. Long noncoding RNAs SET-binding factor 2-antisense RNA1 promotes cell growth through targeting miR-431-5p/CDK14 axis in human papillary thyroid cancer. Kaohsiung J Med Sci. 2020;36(10):808-16.

41. Yang $X$, Zhang $Y$, Fan H. Downregulation of SBF2-AS1 functions as a tumor suppressor in clear cell renal cell carcinoma by inhibiting miR338-3p-targeted ETS1. Cancer Gene Ther. 2020. https://doi.org/10. 1038/s41417-020-0197-4

42. Yu Z, Wang G, Zhang C, Liu Y, Chen W, Wang H, Liu H. LncRNA SBF2-AS1 affects the radiosensitivity of non-small cell lung cancer via modulating microRNA-302a/MBNL3 axis. Cell Cycle. 2020;19(3):300-16.

43. Yin Z, Zhou Y, Ma T, Chen S, Shi N, Zou Y, Hou B, Zhang C. Down-regulated InCRNA SBF2-AS1 in M2 macrophage-derived exosomes elevates miR-122-5p to restrict XIAP, thereby limiting pancreatic cancer development. J Cell Mol Med. 2020;24(9):5028-38.

44. Dai JH, Huang WZ, Li C, Deng J, Lin SJ, Luo J. Silencing of long noncoding RNA SBF2-AS1 inhibits proliferation, migration and invasion and contributes to apoptosis in osteosarcoma cells by upregulating microRNA-30a to suppress FOXA1 expression. Cell Cycle. 2019;18(20):2727-41.

45. Zha W, Li X, Tie X, Xing Y, Li H, Gao F, Ye T, Du W, Chen R, Liu Y. The molecular mechanisms of the long noncoding RNA SBF2-AS1 in regulating the proliferation of oesophageal squamous cell carcinoma. Sci Rep. 2021. https://doi.org/10.1038/s41598-020-80817-w.

46. Wang A, Wang J. E2F1-induced overexpression of long noncoding RNA SBF2-AS1 promotes non-small-cell lung cancer metastasis through regulating miR-362-3p/GRB2 axis. DNA Cell Biol. 2020;39(7):1290-8.

47. Qi H, Wang L, Zhang X, Sun W, Liu J. LncRNA SBF2-AS1 inhibits apoptosis and promotes proliferation in lung cancer cell via regulating FOXM1. J BUON. 2020;25(4):1761-70.

48. Chen R, Xia W, Wang S, Xu Y, Ma Z, Xu W, Zhang E, Wang J, Fang T, Zhang Q, et al. Long noncoding RNA SBF2-AS1 is critical for tumorigenesis of early-stage lung adenocarcinoma. Mol Ther Nucleic Acids. 2019;16:543-53.

49. Sung H, Ferlay J, Siegel RL, Laversanne M, Soerjomataram I, Jemal A, Bray F. Global cancer statistics 2020: GLOBOCAN estimates of incidence and mortality worldwide for 36 cancers in 185 countries. CA Cancer J Clin. 2021. https://doi.org/10.3322/caac.21660.

50. Chen Q, Guo SM, Huang HQ, Huang GP, Li Y, Li ZH, Huang R, Xiao L, Fan CR, Yuan Q, et al. Long noncoding RNA SBF2-AS1 contributes to the growth and metastatic phenotypes of NSCLC via regulating miR338-3p/ADAM17 axis. Aging. 2020;12(18):17902-20.
51. Dawkins J, Webster RM. The hepatocellular carcinoma market. Nat Rev Drug Discov. 2019;18(1):13-4.

52. Yang JD, Hainaut $P$, Gores GJ, Amadou A, Plymoth A, Roberts LR. A global view of hepatocellular carcinoma: trends, risk, prevention and management. Nat Rev Gastroenterol Hepatol. 2019;16(10):589-604.

53. Lamouille S, Xu J, Derynck R. Molecular mechanisms of epithelial-mesenchymal transition. Nat Rev Mol Cell Biol. 2014;15(3):178-96.

54. Wang Y, Liu Z, Yao B, Li Q, Wang L, Wang C, Dou C, Xu M, Liu Q, Tu K. Long non-coding RNA CASC2 suppresses epithelial-mesenchymal transition of hepatocellular carcinoma cells through CASC2/miR-367/ FBXW7 axis. Mol Cancer. 2017;16(1):123.

55. Wang R, Yu Z, Chen F, Xu H, Shen S, Chen W, Chen L, Su Q, Zhang L, Bi $J$, et al. miR-300 regulates the epithelial-mesenchymal transition and invasion of hepatocellular carcinoma by targeting the FAK/PI3K/AKT signaling pathway. Biomed Pharmacother. 2018;103:1632-42.

56. Zhang YT, Li BP, Zhang B, Ma P, Wu QL, Ming L, Xie LM. LncRNA SBF2AS1 promotes hepatocellular carcinoma metastasis by regulating EMT and predicts unfavorable prognosis. Eur Rev Med Pharmacol Sci. 2018;22(19):6333-41.

57. Zhou A, Liu H, Tang B. Comprehensive evaluation of endocytosis-associated protein SCAMP3 in hepatocellular carcinoma. Pharmgenomics Pers Med. 2020;13:415-26.

58. Arnold M, Soerjomataram I, Ferlay J, Forman D. Global incidence of oesophageal cancer by histological subtype in 2012. Gut. 2015;64(3):381-7.

59. Reichenbach ZW, Murray MG, Saxena R, Farkas D, Karassik EG, Klochkova A, Patel K, Tice C, Hall TM, Gang J, et al. Clinical and translational advances in esophageal squamous cell carcinoma. Adv Cancer Res. 2019;144:95-135.

60. Jugniot N, Bam R, Meuillet EJ, Unger EC, Paulmurugan R. Current status of targeted microbubbles in diagnostic molecular imaging of pancreatic cancer. Bioeng Transl Med. 2021;6(1): e10183.

61. Avula LR, Hagerty B, Alewine C. Molecular mediators of peritoneal metastasis in pancreatic cancer. Cancer Metastasis Rev. 2020;39(4):1223-43.

62. Fu XL, Duan W, Su CY, Mao FY, Lv YP, Teng YS, Yu PW, Zhuang Y, Zhao YL. Interleukin 6 induces M2 macrophage differentiation by STAT3 activation that correlates with gastric cancer progression. Cancer Immunol Immunother. 2017;66(12):1597-608.

63. Gowda R, Robertson BM, Iyer S, Barry J, Dinavahi SS, Robertson GP. The role of exosomes in metastasis and progression of melanoma. Cancer Treat Rev. 2020;85: 101975.

64. Lan B, Zeng S, Grützmann R, Pilarsky C. The role of exosomes in pancreatic cancer. Int J Mol Sci. 2019. https://doi.org/10.3390/ijms20184332.

65. Hsieh HY, Chuang HC, Shen FH, Detroja K, Hsin LW, Chen CS. Targeting breast cancer stem cells by novel HDAC3-selective inhibitors. Eur J Med Chem. 2017;140:42-51.

66. He P, Li K, Li SB, Hu TT, Guan M, Sun FY, Liu WW. Upregulation of AKAP12 with HDAC3 depletion suppresses the progression and migration of colorectal cancer. Int J Oncol. 2018;52(4):1305-16.

67. Bharathy N, Berlow NE, Wang E, Abraham J, Settelmeyer TP, Hooper JE, Svalina MN, Ishikawa Y, Zientek K, Bajwa Z, et al. The HDAC3-SMARCA4miR-27a axis promotes expression of the PAX3:FOXO1 fusion oncogene in rhabdomyosarcoma. Sci Signal. 2018. https://doi.org/10.1126/scisi gnal.aau7632

68. Oliveira C, Pinheiro H, Figueiredo J, Seruca R, Carneiro F. Familial gastric cancer: genetic susceptibility, pathology, and implications for management. Lancet Oncol. 2015;16(2):e60-70.

69. Li X, Pasche B, Zhang W, Chen K. Association of MUC16 mutation with tumor mutation load and outcomes in patients with gastric cancer. JAMA Oncol. 2018;4(12):1691-8.

70. Cai H, Jing C, Chang X, Ding D, Han T, Yang J, Lu Z, Hu X, Liu Z, Wang J, et al. Mutational landscape of gastric cancer and clinical application of genomic profiling based on target next-generation sequencing. J Transl Med. 2019;17(1):189.

71. Braun K, Ahluwalia MS. Treatment of glioblastoma in older adults. Curr Oncol Rep. 2017;19(12):81.

72. Korja M, Raj R, Seppä K, Luostarinen T, Malila N, Seppälä M, Mäenpää H, Pitkäniemi J. Glioblastoma survival is improving despite increasing 
incidence rates: a nationwide study between 2000 and 2013 in Finland. Neuro Oncol. 2019;21(3):370-9.

73. Cloughesy TF, Mochizuki AY, Orpilla JR, Hugo W, Lee AH, Davidson TB, Wang AC, Ellingson BM, Rytlewski JA, Sanders CM, et al. Neoadjuvant anti-PD-1 immunotherapy promotes a survival benefit with intratumoral and systemic immune responses in recurrent glioblastoma. Nat Med. 2019;25(3):477-86.

74. Ahir BK, Engelhard HH, Lakka SS. Tumor development and angiogenesis in adult brain tumor: glioblastoma. Mol Neurobiol. 2020;57(5):2461-78.

75. Cai H, Liu X, Zheng J, Xue Y, Ma J, Li Z, Xi Z, Li Z, Bao M, Liu Y. Long non-coding RNA taurine upregulated 1 enhances tumor-induced angiogenesis through inhibiting microRNA-299 in human glioblastoma. Oncogene. 2017;36(3):318-31.

76. Jiang X, Yan Y, Hu M, Chen X, Wang Y, Dai Y, Wu D, Wang Y, Zhuang Z, Xia $\mathrm{H}$. Increased level of $\mathrm{H} 19$ long noncoding RNA promotes invasion, angiogenesis, and stemness of glioblastoma cells. J Neurosurg. 2016;2016(1):129-36.

77. Uyar D, Rader J. Genomics of cervical cancer and the role of human papillomavirus pathobiology. Clin Chem. 2014:60(1):144-6.

78. Cohen PA, Jhingran A, Oaknin A, Denny L. Cervical cancer. Lancet. 2019:393(10167):169-82

79. Dohner H, Weisdorf DJ, Bloomfield CD. Acute myeloid leukemia. N Engl J Med. 2015;373(12):1136-52.

80. Khwaja A, Bjorkholm M, Gale RE, Levine RL, Jordan CT, Ehninger G, Bloomfield CD, Estey E, Burnett A, Cornelissen JJ, et al. Acute myeloid leukaemia. Nat Rev Dis Primers. 2016. https://doi.org/10.1038/nrdp. 2016.10.

81. Cancer Genome Atlas Research Network, Ley TJ, Miller C, Ding L, Raphael BJ, Mungall AJ, Robertson A, Hoadley K, Triche TJ Jr, Laird PW, et al. Genomic and epigenomic landscapes of adult de novo acute myeloid leukemia. N Engl J Med. 2013;368(22):2059-74.

82. Sun LY, Li XJ, Sun YM, Huang W, Fang K, Han C, Chen ZH, Luo XQ Chen YQ, Wang WT. LnCRNA ANRIL regulates AML development through modulating the glucose metabolism pathway of AdipoR1/ AMPK/SIRT1. Mol Cancer. 2018;17(1):127.

83. Fernando TR, Contreras JR, Zampini M, Rodriguez-Malave NI, Alberti MO, Anguiano J, Tran TM, Palanichamy JK, Gajeton J, Ung NM, et al. The IncRNA CASC15 regulates SOX4 expression in RUNX1-rearranged acute leukemia. Mol Cancer. 2017;16(1):126

84. Zhao W, Geng D, Li S, Chen Z, Sun M. LncRNA HOTAIR influences cell growth, migration, invasion, and apoptosis via the miR-20a-5p/ HMGA2 axis in breast cancer. Cancer Med. 2018;7(3):842-55.

85. Kong $X$, Duan Y, Sang Y, Li Y, Zhang H, Liang Y, Liu Y, Zhang N, Yang Q. LnCRNA-CDC6 promotes breast cancer progression and function as ceRNA to target CDC6 by sponging microRNA-215. J Cell Physiol. 2019;234(6):9105-17.

86. Müller V, Oliveira-Ferrer L, Steinbach B, Pantel K, Schwarzenbach H. Interplay of IncRNA H19/miR-675 and IncRNA NEAT1/miR-204 in breast cancer. Mol Oncol. 2019;13(5):1137-49.

87. Mirabello L, Troisi RJ, Savage SA. Osteosarcoma incidence and survival rates from 1973 to 2004: data from the surveillance, epidemiology, and end results program. Cancer. 2009;115(7):1531-43.

88. Harrison DJ, Geller DS, Gill JD, Lewis VO, Gorlick R. Current and future therapeutic approaches for osteosarcoma. Expert Rev Anticancer Ther. 2018;18(1):39-50.

89. Fu G, Polyakova O, MacMillan C, Ralhan R, Walfish PG. Programmed death-ligand 1 expression distinguishes invasive encapsulated follicular variant of papillary thyroid carcinoma from noninvasive follicular thyroid neoplasm with papillary-like nuclear features. EBioMedicine. 2017;18:50-5.

90. Bi W, Huang J, Nie C, Liu B, He G, Han J, Pang R, Ding Z, Xu J, Zhang J. CircRNA circRNA_102171 promotes papillary thyroid cancer progression through modulating CTNNBIP1-dependent activation of B-catenin pathway. J Exp Clin Cancer Res. 2018;37(1):275.

91. McLeod DSA, Zhang L, Durante C, Cooper DS. Contemporary debates in adult papillary thyroid cancer management. Endocr Rev. 2019;40(6):1481-99.

92. Zhang Y, Fang L, Zang Y, Ren J, Xu Z. CIP2A promotes proliferation, invasion and chemoresistance to cisplatin in renal cell carcinoma. $J$ Cancer. 2018;9(21):4029-38.
93. Chittock EC, Latwiel S, Miller TC, Müller CWMolecular architecture of polycomb repressive complexes. Biochem Soc Trans. 2017:45(1):193-205.

94. Kohlmaier A, Savarese F, Lachner M, Martens J, Jenuwein T, Wutz A. A chromosomal memory triggered by Xist regulates histone methylation in X inactivation. PLoS Biol. 2004;2(7):E171.

95. Davidovich C, Zheng L, Goodrich KJ, Cech TR. Promiscuous RNA binding by Polycomb repressive complex 2. Nat Struct Mol Biol. 2013:20(11):1250-57.

96. Maik-Rachline G, Hacohen-Lev-Ran A, Seger R. Nuclear ERK: mechanism of translocation, substrates, and role in cancer. Int J Mol Sci. 2019. https://doi.org/10.3390/ijms20051194.

97. Shopit A, Niu M, Wang H, Tang Z, Li X, Tesfaldet T, Ai J, Ahmad N, Al-Azab $\mathrm{M}$, Tang Z. Protection of diabetes-induced kidney injury by phosphocreatine via the regulation of ERK/Nrf2/HO-1 signaling pathway. Life Sci. 2020;242: 117248

98. Malagrinò F, Coluccia A, Bufano M, Regina G, Puxeddu M, Toto A, Visconti L, Paone A, Magnifico MC, Troilo F, et al. Targeting the interaction between the SH3 domain of Grb2 and Gab2. Cells. 2020. https://doi. org/10.3390/cells9112435.

99. Jiang W, Wei K, Pan C, Li H, Cao J, Han X, Tang Y, Zhu S, Yuan W, He Y, et al. MicroRNA-1258 suppresses tumour progression via GRB2/Ras/Erk pathway in non-small-cell lung cancer. Cell Prolif. 2018;51(6): e12502.

100. Li J, Hu M, Liu N, Li H, Yu Z, Yan Q, Zhou M, Wang Y, Song Y, Pan G, et al. HDAC3 deteriorates colorectal cancer progression via microRNA296-3p/TGIF1/TGF $\beta$ axis. J Exp Clin Cancer Res. 2020;39(1):248.

101. Cabili MN, Trapnell C, Goff L, Koziol M, Tazon-Vega B, Regev A, Rinn $J$ L. Integrative annotation of human large intergenic noncoding RNAs reveals global properties and specific subclasses. Genes Dev. 2011;25(18):1915-27.

102. Wang L, Cho KB, Li Y, Tao G, Xie Z, Guo B. Long noncoding RNA (IncRNA)-mediated competing endogenous RNA networks provide novel potential biomarkers and therapeutic targets for colorectal cancer. Int J Mol Sci. 2019. https://doi.org/10.3390/ijms20225758.

103. Bouchie A. First microRNA mimic enters clinic. Nat Biotechnol. 2013;31(7):577.

104. Meng L, Ward AJ, Chun S, Bennett CF, Beaudet AL, Rigo F. Towards a therapy for Angelman syndrome by targeting a long non-coding RNA. Nature. 2015;518(7539):409-12.

105. Ang L, Guo L, Wang J, Huang J, Lou X, Zhao M. Oncolytic virotherapy armed with an engineered interfering IncRNA exhibits antitumor activity by blocking the epithelial mesenchymal transition in triple-negative breast cancer. Cancer Lett. 2020;479:42-53.

106. Wahlestedt C. Targeting long non-coding RNA to therapeutically upregulate gene expression. Nat Rev Drug Discovery. 2013;12(6):433-46.

107. Jiang MC, Ni JJ, Cui WY, Wang BY, Zhuo W. Emerging roles of IncRNA in cancer and therapeutic opportunities. Am J Cancer Res. 2019;9(7):1354-66.

108. Chen Y, Li Z, Chen X, Zhang S. Long non-coding RNAs: from disease code to drug role. Acta Pharm Sin B. 2021;11(2):340-54.

109. Bennett CF. Therapeutic antisense oligonucleotides are coming of age. Annu Rev Med. 2019;70:307-21.

110. Stein CA, Castanotto D. FDA-approved oligonucleotide therapies in 2017. Mole Ther. 2017;25(5):1069-75.

111. Gong N, Teng X, Li J, Liang XJ. Antisense oligonucleotide-conjugated nanostructure-targeting IncRNA MALAT1 inhibits cancer metastasis. ACS Appl Mater Interfaces. 2019;11(1):37-42.

112. Li M, Ding X, Zhang Y, Li X, Zhou H, Yang L, Li Y, Yang P, Zhang X, Hu J, et al. Antisense oligonucleotides targeting IncRNA AC104041.1 induces antitumor activity through Wnt2B/B-catenin pathway in head and neck squamous cell carcinomas. Cell Death Dis. 2020;11(8):672.

113. Arun G, Diermeier S, Akerman M, Chang KC, Wilkinson JE, Hearn S, Kim $Y$, MacLeod AR, Krainer AR, Norton L, et al. Differentiation of mammary tumors and reduction in metastasis upon Malat1 IncRNA loss. Genes Dev. 2016;30(1):34-51.

114. Zhen S, Li X. Application of CRISPR-Cas9 for long noncoding RNA genes in cancer research. Hum Gene Ther. 2019;30(1):3-9.

115. Zhuo W, Liu Y, Li S, Guo D, Sun Q, Jin J, Rao X, Li M, Sun M, Jiang M, et al. Long noncoding RNA GMAN, up-regulated in gastric cancer tissues, is associated with metastasis in patients and promotes translation 
of ephrin A1 by competitively binding GMAN-AS. Gastroenterology. 2019;156(3):676-691.e611.

116. Ali HS, Boshra MS, El Meteini MS, Shafei AE, Matboli M. IncRNA-RP11156p1.3, novel diagnostic and therapeutic targeting via CRISPR/Cas9 editing in hepatocellular carcinoma. Genomics. 2020;112(5):3306-14.

117. Ren Y, Wang YF, Zhang J, Wang QX, Han L, Mei M, Kang CS. Targeted design and identification of AC1NOD4Q to block activity of HOTAIR by abrogating the scaffold interaction with $\mathrm{EZ} \mathrm{H} 2$. Clin Epigenet. 2019:11(1):29.

118. Dhillon S. Risdiplam: first approval. Drugs. 2020;80(17):1853-8.

119. Guo H, Liu J, Ben Q, Qu Y, Li M, Wang Y, Chen W, Zhang J. The aspirininduced long non-coding RNA OLA1P2 blocks phosphorylated STAT3 homodimer formation. Genome Biol. 2016;17:24.

120. Juru AU, Hargrove AE. Frameworks for targeting RNA with small molecules. J Biol Chem. 2020. https://doi.org/10.1074/jbc.REV120.015203.

121. Mercatelli N, Fortini D, Palombo R, Paronetto MP. Small molecule inhibition of Ewing sarcoma cell growth via targeting the long non coding RNA HULC. Cancer Lett. 2020;469:111-23.
122. Zhou Q, Hou Z, Zuo S, Zhou X, Feng Y, Sun Y, Yuan X. LUCAT1 promotes colorectal cancer tumorigenesis by targeting the ribosomal protein L40-MDM2-p53 pathway through binding with UBA52. Cancer Sci. 2019;110(4):1194-207.

123. Huan L, Guo T, Wu Y, Xu L, Huang S, Xu Y, Liang L, He X. Hypoxia induced LUCAT1/PTBP1 axis modulates cancer cell viability and chemotherapy response. Mol Cancer. 2020;19(1):11.

124. Zhao QS, Li L, Zhang L, Meng XW, Li LL, Ge XF, Li ZP. Over-expression of InCRNA SBF2-AS1 is associated with advanced tumor progression and poor prognosis in patients with non-small cell lung cancer. Eur Rev Med Pharmacol Sci. 2016;20(14):3031-4

125. Zhang Y, LiY, Han L, Zhang P, Sun S. SBF2-AS1: an oncogenic IncRNA in small-cell lung cancer. J Cell Biochem. 2019;120(9):15422-8.

\section{Publisher's Note}

Springer Nature remains neutral with regard to jurisdictional claims in published maps and institutional affiliations.
Ready to submit your research? Choose BMC and benefit from:

- fast, convenient online submission

- thorough peer review by experienced researchers in your field

- rapid publication on acceptance

- support for research data, including large and complex data types

- gold Open Access which fosters wider collaboration and increased citations

- maximum visibility for your research: over 100M website views per year

At BMC, research is always in progress.

Learn more biomedcentral.com/submissions 